\title{
A study on efficacy of ambroxol in the treatment of acute bronchitis in tertiary care hospital
}

\author{
V. Jaya Wardhani ${ }^{1}$, Nagawaram P. Rao ${ }^{2 *}$
}

Department of Pharmacology, Dr Patnam Mahender Reddy Institute of Medical Sciences \& Hospital, Chevella, R.R District, Telangana, India

Received: 02 September 2020

Revised: 16 September 2020

Accepted: 17 September 2020

\section{*Correspondence:}

Dr. Nagawaram P. Rao,

Email: jayawardhani@gmail.com

Copyright: () the author(s), publisher and licensee Medip Academy. This is an open-access article distributed under the terms of the Creative Commons Attribution Non-Commercial License, which permits unrestricted non-commercial use, distribution, and reproduction in any medium, provided the original work is properly cited.

\section{ABSTRACT}

Background: Upper respiratory tract infections (URTI), including acute bronchitis, are the frequent health problems and the most common reason for acute cough in adults. Even though the infections are caused mainly by viruses, and their course is usually not complicated, febrifuges, i.a. mucokinetics, or antitussives are used in the treatment of URTI in order to improve the quality of life and safety of patients.

Methods: The present study was prospective and observational study. Data from adult patients treated with ambroxol hydrochloride for acute bronchitis were collected and compared with data from patients treated for the same condition without ambroxol preparations. The severity of bronchitis symptoms was evaluated with the respiratory rate, retraction score, wheezing score and oxygen saturation (SPO2) between visits patients conducted self-observations and filled out observation diaries. Baseline clinical symptomatolgy of breathlessness, cough, and sputum severity scoring were compared before and after 3 and 7 days of treatment in both groups.

Results: Majority of the patient's infections were cured. Most of patients considered the studied drugs to be the agent decreasing the duration of infection and its intensity. The percentage of patients who declared that they had a less intense cough than during earlier infections was higher in the group of patients treated with ambroxol treated patients. Patients treated with Ambroxol hydrochloride to be very safe.

Conclusions: Ambroxol is an efficient, well-tolerated, and safe drug. Its efficacy in the treatment of acute bronchitis symptoms in adult patients is similar to the efficacy of other preparations.

Keywords: Ambroxol, Bronchitis, Efficacy, Oxygen saturation

\section{INTRODUCTION}

Acute bronchitis (CB) is a progressive disease characterized by chronic increase in the production of mucous. It is defined as the presence of a chronic cough with sputum production for at least three months, in each of two consecutive years, after other causes of cough, such as tuberculosis and lung cancer, have been eliminated. ${ }^{1}$ Acute bronchitis are defined as recurrent attacks of worsening bronchial inflammation that occur on average 1.5-3 times a year, and are superimposed on baseline $\mathrm{CB}$. These exacerbations are marked by an increase in the volume of daily sputum produced; a change in colour of the expectorated sputum (ie, darker, more yellow, greener) and worsening dyspnea. ${ }^{2}$

Ambroxol has mucoactive, anti-inflammatory, antioxidant and surfactant-promoting properties. Moreover, it gets concentrated selectively in lungs, Though clinical data are scanty, ambroxol safe and economical drug may be considered for treatment of acute respiratory distress syndrome (ARDS) for its potential to improve gas exchange. ${ }^{2-10}$ If clinical efficacy 
could be established, ambroxol would be an attractive therapeutic option for its low cost and toxicity. Ambroxol is a metabolite of bromhexine and is widely used as a mucolytic. It also induces the synthesis of surfactant in lung alveolar type II cells. By this mechanism, it decreases the work and effort of breathing and can improve respiratory symptoms.

The aim of the present study to identify the efficacy of ambroxol in the treatment of acute bronchitis in adult.

\section{METHODS}

\section{Study design}

It was a prospective observational study, designed to determine the efficacy of ambroxol hydrochloride in reducing clinical symptom scores under conditions that reflect the usual medical care for $\mathrm{AB}$ (defined as worsening of the baseline symptoms (cough, sputum, and breathlessness of $\mathrm{AB}$ ), was conducted.

\section{Study place}

It was carried out at, Department of Pharmacology, Dr Patnam Mahender Reddy Institute of Medical Sciences \& Hospital, Chevella, R.R District, Telangana, India

\section{Study period}

The study was conducted at tertiary care hospital, from January 2020 to August 2020.

\section{Selection of the patients}

\section{Inclusion criteria}

Patients were eligible for inclusion in the study if they were a male or female aged 20-30 years, with a history of smoking and a physician's diagnosis of acute bronchitis. The diagnosis of $\mathrm{AB}$ was based on the history of cough and expectoration on most days during a period of at least three consecutive months for two consecutive years.

\section{Exclusion criteria}

Patients were excluded if they had any of the following conditions: heart failure or multiple organ dysfunctions: bronchiectasis; bronchial carcinoma; interstitial lung disease; pneumonia; inability to comply with the study procedures because of dementia; or if they had any other medical problems that in the opinion of the investigator would interfere with the conduct of study.

\section{Procedure}

This study was observational study, to identify the efficacy of administration of ambroxol hydrochloride compared to without giving ambroxol in adults for management of acute bronchitis.
The randomization is done from random table where in first subject will be assigned 1st group second group as 2nd. The two repulse, one with without ambroxol and other with ambroxol hydrochloride.

Cases were allocated to $30 \mathrm{mg}$ or without drug. Study drug was administered every 6th hourly. Study drug was delivered tablet form by oral administration. The drug was given two times per day.

Evaluation done by the parameters which will reflect the state of pulmonary functions like respiratory rate, retraction score (0-3) which include no retraction, intercostals retraction, sub coastal retraction and suprasternal retraction; wheezing score(0-3) which is absent (0), endiexpiratory (1), panexpiratory (2), and audible to naked ear (3); oxygen saturation, pulse rate, sensorium and cyanosis. Oxygen saturation was measured using a pulse oxymeter after breathing room air for at least 10 minutes. Evaluation is done at $0 \mathrm{hrs}$., 6 hrs., 12 hrs., 24 hrs., 36 hrs., 48 hrs., and 72 hrs. after admission.

Breathlessness was measured on a 7-point Likert scale. Severity of cough and sputum clearance was measured using the Modified questionnaire for ease of cough and sputum clearance. At the end of one week treatment, all patients were asked to grade their impression of improvement or change in their condition using the clinical global impression of improvement or change scale (CGIC), which is a 7-point rated scale where $0=$ not assessed; 1=very much improved; 2=much improved; $3=$ minimally improved; $4=$ no change; $5=$ minimally worsened; 6=much worsened; and 7=very much worsened. Finally, all subjects were interrogated about any possible adverse effects.

\section{Ethical approval}

Study was approved by the Ethics Committee and all participants provided written informed consent.

\section{Statistical analysis}

To detect a difference in the mean severity of cough and expectoration score between the two treatment groups of 4 points with a standard deviation (SD) of 5; a p-value, 0.05 ; and an approximate power of $90 \%$, we calculated the minimal needed sample size to be 65 patients. All randomized adults were considered in the analysis. The mean analysis was compared between groups and time point by repeated measures ANOVA.

\section{RESULTS}

\section{Age incidence}

In this study most of the cases (24) was observed in the age range between the $20-30$ yrs $(80 \%)$. 


\section{Monthly admission}

All 30 cases were studied during that period. Irritability noted in 11 cases at the time of admission out of 11 cases, 7 cases were studied with Ambroxol in which irritability persisted upto 24 hrs and cases were studied with normal saline in which irritability persisted up to $12 \mathrm{hrs}$ from admission. In all 30 cases stastically significant in clinical improvement over 3 days. $(\mathrm{p}<0.000)$.

However, by adjusting the baseline value for SPO2 there was no statistical significance between groups in SPO2, there was a improvement in respiratory rate $(\mathrm{p}=0.775)$ and retraction score $(\mathrm{p}=0.102)$ in normal saline cases compared to ambroxol hydrochloride cases but not statistical significant.
All cases were discharged after 3 days of admission, as all cases were improved clinically over 3 days.

The present study showed that, there was a improvement in respiratory rate $(\mathrm{p}=0.775)$ and retraction score $(\mathrm{p}=0.102)$ in normal saline cases compared to ambroxol hydrochloride cases but not statistical significant (Table 1) \& (Table 2).

Statistical significance $(\mathrm{p}=0.040)$ in wheezing score with normal saline, compared to ambroxol Hydrochloride present at $6^{\text {th }} \mathrm{hr}, 12^{\text {th }} \mathrm{hr}$, and $36^{\text {th }} \mathrm{hr}$ only and there was no statistical significance at $0 \mathrm{hr} 24^{\text {th }} \mathrm{hr}, 48^{\text {th }} \mathrm{hrs}$ and $72 \mathrm{nd}$ $\mathrm{hr}$. Because of the difference in SPO2 between groups at baseline level, there was statistical significance $(\mathrm{p}=0.033)$ in favour of normal saline (Table 3) \& (Table 4).

Table 1: Respiratory rate of patients.

\begin{tabular}{|llll|}
\hline \multirow{2}{*}{ Rroups } & & Mean \pm SD & No of patients \\
\hline \multirow{2}{*}{ RR6 } & Group 1 & $84.00 \pm 13.72$ & 20 \\
\cline { 2 - 4 } & Group 2 & $85.13 \pm 9.93$ & 10 \\
\hline \multirow{2}{*}{ RR12 } & Group 1 & $78.20 \pm 13.83$ & 20 \\
\hline \multirow{2}{*}{ RR24 } & Group 2 & $78.08 \pm 12.14$ & 10 \\
\hline \multirow{2}{*}{ RR36 } & Group 1 & $72.11 \pm 14.23$ & 20 \\
\hline \multirow{2}{*}{ RR48 } & Group 2 & $72.20 \pm 11.81$ & 20 \\
\hline \multirow{2}{*}{ RR72 } & Group 1 & $66.89 \pm 14.60$ & 10 \\
\hline & Group 2 & $66.27 \pm 11.48$ & 20 \\
\hline Groups & Group 1 2 & $61.09 \pm 13.28$ & 10 \\
\hline Time & Group 1 & $58.67 \pm 12.72$ & 20 \\
\hline & Group 2 & $54.37 \pm 11.28$ & 10 \\
\hline & Group 1 & $52.43 \pm 13.63$ & 20 \\
\hline & Group 2 & $44.46 \pm 9.32$ & 10 \\
\hline
\end{tabular}

Table 2: Retraction score.

\begin{tabular}{|llll|}
\hline Groups & & Mean \pm SD & No of patients \\
\hline \multirow{2}{*}{ RTS6 } & Group 1 & $2.91 \pm 0.28$ & 20 \\
\cline { 2 - 3 } & Group 2 & $2.90 \pm 0.30$ & 10 \\
\hline \multirow{2}{*}{ RTS12 } & Group 1 & $2.91 \pm 0.28$ & 20 \\
\hline \multirow{2}{*}{ RTS24 } & Group 2 & $2.73 \pm 0.45$ & 10 \\
\hline \multirow{2}{*}{ RTS36 } & Group 1 & $2.71 \pm 0.45$ & 20 \\
\hline \multirow{2}{*}{ RTS48 } & Group 2 & $2.53 \pm 0.68$ & 20 \\
\hline \multirow{2}{*}{ RTS72 } & Group 1 & $2.34 \pm 0.68$ & 10 \\
\hline \multirow{2}{*}{ Group 2 } & Group 1 & $2.10 \pm 0.84$ & 20 \\
\hline Time & Group 2 & $1.11 \pm 0.71$ & 10 \\
\hline
\end{tabular}


Table 3: Wheezing score.

\begin{tabular}{|llll|}
\hline Groups & & Mean \pm SD & No of patients \\
\hline \multirow{2}{*}{ WZS6 } & Group 1 & $2.77 \pm 0.42$ & 20 \\
& Group 2 & $2.67 \pm 0.47$ & 10 \\
\hline \multirow{2}{*}{ WZS12 } & Group 1 & $2.69 \pm 0.47$ & 20 \\
& Group 2 & $2.43 \pm 0.50$ & 10 \\
\hline \multirow{2}{*}{ WZS24 } & Group 1 & $2.51 \pm 0.56$ & 10 \\
\hline \multirow{2}{*}{ WZS36 } & Group 2 & $2.20 \pm 0.48$ & 20 \\
\hline \multirow{2}{*}{ WZS48 } & Group 1 & $2.14 \pm 0.64$ & 10 \\
\hline \multirow{2}{*}{ WZS72 } & Group 2 & $1.90 \pm 0.60$ & 20 \\
\hline & Group 1 & $1.83 \pm 0.66$ & 10 \\
\hline Groups & Group 2 & $1.43 \pm 0.72$ & 20 \\
\hline Time & Group 1 & $1.31 \pm 0.75$ & 10 \\
\hline
\end{tabular}

Table 4: Oxygen saturation.

\begin{tabular}{|c|c|c|c|}
\hline Groups & & Mean \pm SD & No of patients \\
\hline \multirow{2}{*}{$\mathrm{SPO}_{2} \mathrm{O}$} & Group 1 & $85.66 \pm 6.07$ & 20 \\
\hline & Group 2 & $88.73 \pm 3.72$ & 10 \\
\hline \multirow{2}{*}{$\mathrm{SPO}_{2} 6$} & Group 1 & $88.03 \pm 5.36$ & 20 \\
\hline & Group 2 & $90.40 \pm 3.57$ & 10 \\
\hline \multirow{2}{*}{$\mathrm{SPO}_{2} 12$} & Group 1 & $90.31 \pm 4.89$ & 20 \\
\hline & Group 2 & $92.33 \pm 3.10$ & 10 \\
\hline \multirow{2}{*}{$\mathrm{SPO}_{2} 24$} & Group 1 & $92.17 \pm 3.64$ & 20 \\
\hline & Group 2 & $93.87 \pm 2.52$ & 10 \\
\hline \multirow{2}{*}{$\mathrm{SPO}_{2} 36$} & Group 1 & $93.91 \pm 2.95$ & 20 \\
\hline & Group 2 & $92.57 \pm 2.37$ & 10 \\
\hline \multirow{2}{*}{$\mathrm{SPO}_{2} 48$} & Group 1 & $95.63 \pm 2.70$ & 20 \\
\hline & Group 2 & $96.40 \pm 2.12$ & 10 \\
\hline \multirow{3}{*}{$\mathrm{SPO}_{2} 72$} & Group 1 & $97.74 \pm 1.59$ & 20 \\
\hline & Group 2 & $98.07 \pm 1.23$ & 10 \\
\hline & F ratio & $P$ value & \\
\hline Groups & 4.770 & 0.003 & significant \\
\hline Time & 210.15 & 0.000 & Significant \\
\hline
\end{tabular}

Table 5: Age incidence.

\begin{tabular}{|l|l|}
\hline Age in yrs & No of cases \\
\hline $\mathbf{0 - 1 0}$ & 00 \\
\hline $\mathbf{1 1 - 2 0}$ & 00 \\
\hline $\mathbf{2 1 - 3 0}$ & 24 \\
\hline $\mathbf{3 1 - 4 0}$ & 04 \\
\hline $\mathbf{4 1 - 5 0}$ & 01 \\
\hline $\mathbf{5 1 - 6 0}$ & 01 \\
\hline $\mathbf{6 1 - 7 0}$ & 00 \\
\hline
\end{tabular}

In the present study, However, by adjusting the baseline value for SPO2 there was no statistical significance between groups in SPO2 (Table 4).
In the present study most of the bronchitis cases were observed age between 21-30 yrs. (Table 5).

There was a statistically significant improvement of breathlessness and cough scoring in both groups when compared before and after treatment at day 3 and at day 7 (Tables 6) and (Table 7), using a nonparametric related samples Friedman test $(\mathrm{p}=0.05)$. There was a highly statistically significant difference in improvement in breathlessness score, as well as cough score, in favor of ambroxol treatment when compared with without using ambroxol treated group. 
Table 6: Related samples Friedman test for breathlessness scoring in each group.

\begin{tabular}{|c|c|c|c|}
\hline & Measure & No & Median \\
\hline \multirow{3}{*}{$\begin{array}{l}\text { Ambroxol } \\
\text { Hydrochloride }\end{array}$} & $\begin{array}{l}\text { Pretreatment } \\
\text { breathlessness } \\
\text { score }\end{array}$ & 20 & 5 \\
\hline & $\begin{array}{l}\text { Breathlessness } \\
\text { score at day } 3\end{array}$ & 20 & 2 \\
\hline & $\begin{array}{l}\text { Breathlessness } \\
\text { score at day } 7\end{array}$ & 20 & 1 \\
\hline \multirow{3}{*}{$\begin{array}{l}\text { Without } \\
\text { Ambroxol }\end{array}$} & $\begin{array}{l}\text { Pretreatment } \\
\text { breathlessness } \\
\text { score }\end{array}$ & 10 & 4 \\
\hline & $\begin{array}{l}\text { Breathlessness } \\
\text { score at day } 3\end{array}$ & 10 & 3 \\
\hline & $\begin{array}{l}\text { Breathlessness } \\
\text { score at day } 7\end{array}$ & 10 & 2 \\
\hline
\end{tabular}

Table 7: Related samples Friedman test for cough and sputum scoring in each group.

\begin{tabular}{|c|c|c|c|}
\hline & Measure & No & Median \\
\hline \multirow{3}{*}{$\begin{array}{l}\text { Ambroxol } \\
\text { Hydrochloride }\end{array}$} & $\begin{array}{l}\text { Pretreatment } \\
\text { cough score }\end{array}$ & 20 & 12 \\
\hline & $\begin{array}{l}\text { Cough score at } \\
\text { day } 3\end{array}$ & 20 & 08 \\
\hline & $\begin{array}{l}\text { Cough score at } \\
\text { day } 7\end{array}$ & 20 & 02 \\
\hline \multirow{3}{*}{$\begin{array}{l}\text { Without } \\
\text { Ambroxol }\end{array}$} & $\begin{array}{l}\text { Pretreatment } \\
\text { cough score }\end{array}$ & 10 & 5 \\
\hline & $\begin{array}{l}\text { Cough score at } \\
\text { day } 3\end{array}$ & 10 & 03 \\
\hline & $\begin{array}{l}\text { Cough score at } \\
\text { day } 7\end{array}$ & 10 & 2 \\
\hline
\end{tabular}

Out of 30 patients, $25(83.33 \%)$ in the ambroxol hydrochloride treated group rated their improvement on the CGIC scale as "much" and "very much" improved, while only a smaller number of patients reported the same degree of improvement in the without taking group. The difference was statistically significant $(\mathrm{p}=0.05)$.

\section{DISCUSSION}

Ambroxol is an active metabolite of bromhexine and has been established for decades in the treatment of acute (e.g. bronchitis) and chronic respiratory diseases (e.g. COPD). Pharmacological and clinical studies showed the mucoregulative and secretagogue properties of ambroxol. These studies previously done by Wang et al. ${ }^{8}$

Positive effects have been seen with the use of ambroxol in patients with early hypersecretory $\mathrm{CB}$, including improvement in coughing; dyspnea; color and consistency of sputum; and ease of expectoration, when compared to a control.
In the present study, most of the cases of bronchitis (24 out of $30-80 \%$ ) are between $21-30$ yrs. In this study bronchitis cases appeared between August and January months compared to previous studies conduted by Su et al. ${ }^{9}$

In the present studies, statistically significant clinically improvement observed in both the groups over 3 days after admission without significant differences in the both the groups. So the main stay of treatment bronchitis is supportive with other combination of antibiotics (salbutanol).

A randomized controlled method to conduct the clinical study of treatment with ambroxol in 137 patients with bronchitis admitted to the hospital. The results of the study showed that treatment with ambroxol was superior to placebo and normal saline treatment in terms of improvement in clinical status, number of days needed for relives of symptoms (cough) and signs. Their conclusion is that ambroxol is an effective therapeutic approach to acute bronchitis. These results consistent with the previous findings done by Ma et al. ${ }^{10}$

In the present study, though there was a difference in all the parameters in favour of normal saline but statistical analysis only wheezing score at $6^{\text {th }} \mathrm{hr}, 12^{\text {th }} \mathrm{hr}, 36^{\text {th }} \mathrm{hr}$ was significant. Hence Ambroxol hydrochloride administra tion does not differ advantage over the normal saline in decreasing the severity of bronchitis. Our findings were not consistent with other findings done by Ma YT et al. ${ }^{10-}$ 13

There is insufficient evidence to support the use of epinephrine among in patients. Large, multi centered trials were required before routine use among out patients can be strongly recommended.

In the present study, there was improvement clinically among in patients as per the normal course of the disease and hence it was less lightly to be influenced either of the agents.

In the present study there was no morbidity associated after 3 days of treatment compared to above study. There were no side effects noted with normal saline administration in our study compared with epinephrine administration in the above study in which side effects noted such as tachycardia, hypertension etc. However irritability was noted in seven cases studied with Ambroxol observed in previous study made by Ma et al. ${ }^{10}$

This study showed significant improvement in breathlessness and severity of cough scores in patients treated with the ambroxol hydrochloride than those treated with without ambroxol. Ambroxol has been tested in many large multicenter, randomized, double blind controlled studies in cases of $\mathrm{AB}$. The results confirm the previously seen improvement in symptomatology and the significant reduction in number and severity of 
exacerbations in groups. Positive effects have been seen with the use of ambroxol in patients with early hypersecretory $\mathrm{AB}$, including improvement in coughing; dyspnea; color and consistency of sputum; and ease of expectoration, when compared to a control. These findings similar with that of past studies conducted by Ericson et al. ${ }^{14}$

\section{CONCLUSION}

We concluded from our study that ambroxol hydrochloride tablets might be safe and effective in improving symptoms in cases of acute bronchitis.

\section{ACKNOWLEDGEMENTS}

The authors are thankful to Dept of Pharmacology Dr Patnam Mahender Reddy Institute of Medical Sciences \& Hospital, Chevella, R.R District for providing facilities to carry out this work.

\section{Funding: No funding sources}

Conflict of interest: None declared

Ethical approval: The study was approved by the Institutional Ethics Committee

\section{REFERENCES}

1. Wunderer H, Morgenroth K, Weis G. The cleaning system of the airways: physiology, pathophysiology and effects of ambroxol. Med Monatsschr Pharm. 2009;32:42-7.

2. Malerba M, Ragnoli B. Ambroxol in the 21st century:pharmacological and clinical update. Expert Opin Drug Metab Toxicol. 2008;4:1119-29.

3. Li Q, Yao G, Zhu X. High-dose ambroxol reduces pulmonary complications in patients with acute cervical spinalcord injury after surgery. Neurocrit Care. 2012;16:267-72.

4. Wauer RR, Schmalisch G, Böhme B, Arand J, Lehmann D. Randomized double blind trial of Ambroxol for the treatment of respiratory distress syndrome. Europ J Pediatr. 1992;151(5):357-63.

5. Xia DH, Xi L, Xv C, Mao WD, Shen WS, Shu ZQ, et al. The protective effects of ambroxol on radiation lung injury and influence on production of transforming growth factor $\beta 1$ and tumor necrosis factor $\alpha$. Medic Oncol. 2010;27(3):697-701.
6. Ulas MM, Hizarci M, Kunt A, Ergun K, Kocabeyoglu SS, Korkmaz K, et al. Protective effect of ambroxol on pulmonary function after cardiopulmonary bypass. J Cardiovascu Pharmacol. 2008;52(6):518-23.

7. Wang Y, Wang FY, Pan Z, Dai YY, Xu HJ, Jin KK, et al. Effects of ambroxol combined with low-dose heparin on TNF-alpha and IL-1beta in rabbits with acute lung injury. J Appli Physiol. 2011;27(2):231-5.

8. Su X, Wang L, Song Y, Bai C. Inhibition of inflammatory responses by ambroxol, a mucolytic agent, in a murine model of acute lung injury induced by lipopolysaccharide. Intensi Care Medic. 2004;30(1):133-40.

9. Ma YT, Tian YP, Shi HW, Lv CH, Liu JH, Sun ZP. Effects of high dose ambroxol on lung injury induced by paraquat in rats. Chine $\mathbf{J}$ Indust Hygie Occupat Diseas. 2007;25(9):523.

10. ARDS Definition Task Force, Ranieri VM, Rubenfeld GD, Thompson BT, et al. Acute respiratory distress syndrome:the Berlin Definition. Ameri Medic Assoc. 2012;307:2526-33.

11. Schulz M, Hammrlein A, Hinkel U. Safety and usage pattern of an over-the-counter ambroxol cough syrup: a community pharmacy based cohort study. Int J Clin Pharmacol Ther. 2006;44:409-21.

12. Schmalisch G, Wauer RR, Bohme B. Effect of early ambroxol treatment on lung functions in mechanically ventilated preterm newborns who subsequently developed a bronchopulmonary dysplasia. Respir Med. 2000;94:378-84.

13. Ericsson $\mathrm{CH}$, Juhasz J, Jönsson E, Mossberg B. Ambroxol therapy in simple chronic bronchitis: effects on subjective symptoms and ventilatory function. Europ J Respirat Diseas. 1986;69(4): 248-55.

14. Balter MS, La Forge J, Low DE, Mandell L, Grossman RF, Chronic Bronchitis Working Group. Canadian guidelines for the management of acute exacerbations of chronic bronchitis. Canadi Respirat J. $2003 ; 10$.

Cite this article as: Wardhani VJ, Rao NP. A study on efficacy of ambroxol in the treatment of acute bronchitis in tertiary care hospital. Int J Basic Clin Pharmacol 2020;9:1597-602. 